\title{
Detection, Isolation, and Pathogenicity of Colletotrichum spp. from Strawberry Petioles
}

\author{
J. C. Mertely and D. E. Legard, University of Florida, Gulf Coast Research and Education Center, Dover 33527
}

\begin{abstract}
Mertely, J. C., and Legard, D. E. 2004. Detection, isolation, and pathogenicity of Colletotrichum spp. from strawberry petioles. Plant Dis. 88:407-412.

The herbicide paraquat is used to kill plant tissues and accelerate the growth of quiescent fungal colonists. In this study, freezing was investigated as an alternative to paraquat for the detection of latent infections of Colletotrichum spp. on strawberry petioles. Apparently healthy petioles from field-grown plants and inoculated petioles from greenhouse-grown plants were killed by freezing or exposure to $0.3 \%$ paraquat, and incubated in petri dish moist chambers. Previously frozen petioles were treated with 0.525 or $0.0525 \%$ sodium hypochlorite and Tween 20 at 18 $\mu \mathrm{l} /$ liter for selected intervals to test the effects of surface disinfestation on detection frequency. After 5 to 7 days of incubation, Colletotrichum acervuli developed much more frequently on freeze- and paraquat-treated petioles than on washed petioles which were not killed. Detection frequencies were similar for paraquat and some freeze treatments, but the latter were negatively affected by prolonged surface disinfestation. Using the petiole freeze method, Colletotrichum acutatum, C. gloeosporioides, and Glomerella cingulata (the teleomorph of C. gloeosporioides) were detected on symptomless petioles of field-grown plants. In addition, $C$. acutatum and $C$. dermatium were detected on apparently healthy transplants from northern nurseries. All of these fungi are reported pathogens of strawberry, but not all $C$. gloeosporioides isolates from frozen petioles were pathogenic in greenhouse bioassays. Freezing is a viable, nonhazardous alternative to paraquat for the detection of latent Colletotrichum infections on strawberry.
\end{abstract}

Additional keywords: exclusion, quarantine

Colletotrichum spp. cause several diseases of strawberry, the most destructive of which are anthracnose fruit rot and Colletotrichum crown rot. Anthracnose fruit rot usually is caused by Colletotrichum acutatum and is characterized by large, sunken lesions that render the fruit unmarketable (17,30). Colletotrichum crown rot is caused by $C$. fragariae or $C$. gloeosporioides, two species which may be conspecific $(16,33,39)$. Both fungi decay strawberry crowns, resulting in the wilting and death of plants in nurseries and production fields $(17,30)$. C. fragariae was the first reported causal agent of Colletotrichum crown rot $(4,5)$, but $C$. gloeosporioides and its teleomorph Glomerella cingulata usually are associated with the disease in Florida $(16,17$, 20,36). All three species are disseminated on infected transplants $(16,25,30)$, which may or may not show visible symptoms. The objective of this study was to develop an improved method to detect Colleto-

Corresponding author: J. C. Mertely

E-mail: jcmert@ufl.edu

Florida Agricultural Experiment Station Journal Series No. R-09798.

Accepted for publication 18 November 2003.

Publication no. D-2004-0206-02R

(C) 2004 The American Phytopathological Society trichum spp. on apparently healthy strawberry plants.

Researchers have advocated the use of disease-free transplants to avoid outbreaks of Colletotrichum crown rot in strawberry production fields $(17,20,25)$. These recommendations sometimes were based on empirical evidence such as the association of field outbreaks with nursery source. Similar recommendations could be made for $C$. acutatum because this pathogen has been isolated from California nursery plants on several occasions $(8,13)$. These reports resulted in the classification of $C$. acutatum as an organism of quarantine significance in Canada from 1991 to 1997 (PPD directive D-97-03) and in the United Kingdom and the European Community since 1993 (EC directive 77/93). In 1996, Freeman (10) published the first report of anthracnose fruit rot of strawberry in Israel. After examining numerous local isolates and comparing their genetic markers to reference isolates using random amplified polymorphic DNAs, he concluded that a single introduction of $C$. acutatum from the United States was responsible for the outbreak (11). These reports illustrate the importance of early detection of $C$. $a c u$ tatum and exclusion of contaminated planting materials $(1,3,7)$.

Pathogen-free strawberry plants can be obtained by propagating plantlets from meristem culture in areas lacking reservoir hosts (e.g., wild and domesticated straw- berry) or areas outside the normal range of anthracnose pathogens. However, this approach has become less feasible with the northerly spread of $C$. acutatum in the United States and Europe $(3,23,28)$. To produce pathogen-free planting material, nurserymen must identify infected plants before they are sold, which can be difficult. Regular fungicide applications help to limit disease spread in modern nurseries but hinder development of characteristic anthracnose lesions on stolons and petioles. However, even in the absence of visible symptoms, Colletotrichum spp. may persist on plants as microscopic latent infections consisting of appressoria with limited development of infective hyphae $(29,38)$. Their detection by conventional isolation techniques is time consuming. With respect to crown rot, the symptoms are somewhat generalized and may be caused by Macrophomina phaseolina and Phytophthora spp. (22) as well as $C$. fragariae and $C$. gloeosporioides. Isolation and identification, a time-consuming process, must be carried out to determine the etiology of crown rot diseases.

The herbicide paraquat $\left(1,1^{\prime}\right.$-dimethyl4,4'-bipyridinium dichloride) has been used to enhance detection of species of Alternaria, Botrytis, Cercospora, Colletotrichum, Phomopsis, and other fungi on healthyappearing plant material since the $1980 \mathrm{~s}$ $(2,6,12,29,35)$. Chlorophyll-containing tissues are killed rapidly by paraquat, a process that accelerates the growth and sporulation of fungal colonists and some endophytes. Plant parts are treated with 0.03 to $0.6 \%$ of the paraquat cation and incubated under humid conditions to encourage the growth and sporulation of fungal colonists, which are subsequently identified. In the early 1990s, workers at the Central Science Laboratory in Great Britain began using paraquat to detect $C$. acutatum on petioles of imported strawberry plants (7). Unfortunately, paraquat is a hazardous material that is toxic when ingested, inhaled as a mist, or absorbed through the skin or eyes.

In this study, freezing was evaluated as an alternative to paraquat and tested for its ability to differentially kill strawberry tissue without eliminating fungal colonists. The sensitivity of this method was compared with paraquat for the detection of Colletotrichum spp. on strawberry petioles. Strawberry runner plants from Canadian nurseries were assayed using this new methodology. A portion of this study was reported previously (26). 


\section{MATERIALS AND METHODS}

Treatment comparisons using naturally infected strawberry petioles. A paraquat treatment and five freeze treatments were evaluated for their ability to facilitate the detection of latent infections of Colletotrichum spp. in strawberry petioles. The evaluation consisted of six replicate experiments carried out between January and May 2000. Each experiment was initiated by collecting approximately 250 petioles from mature leaves of strawberry plants growing in fields at the Gulf Coast Research and Education Center (GCREC) in Dover, FL. Four experiments were conducted with petioles of the susceptible cv. Camarosa and two with petioles from a mixed group of unnamed clones. Petioles that showed visible lesions or unusual physical damage were discarded. Remaining symptomless petioles were trimmed to a length of 6 to $7 \mathrm{~cm}$ including part of the base with stipules removed. Thirty petioles were selected randomly for each treatment. All treatments were carried out in $125-\mathrm{ml}$ wide-mouth, screw-cap plastic bottles (Nalge Nunc Intl., Rochester, NY), processing five petioles per bottle.

The control treatment consisted of washing petioles in $140 \mathrm{ml}$ of sterile deionized water supplemented with Tween 20 surfactant at $18 \mu \mathrm{l} /$ liter. The bottles were closed and shaken vigorously by hand for two brief intervals during a 60-s wash period. After the wash water was drained, the petioles were rinsed once in sterile deionized water and placed on dry filter paper circles in $9-\mathrm{cm}$ petri dishes, one replicate per dish. The petioles were air dried in a laminar flow hood for 5 to 10 min to remove excess surface moisture. To produce humid incubation conditions, 0.7 $\mathrm{ml}$ of deionized water was added to the filter paper circle in each dish before the lids were replaced. The paraquat treatment consisted of immersing petioles for $60 \mathrm{~s}$ in paraquat cation at $3,000 \mu \mathrm{g} / \mathrm{ml}$ or $0.3 \%$ (29) prepared from Gramoxone Extra (Syngenta Crop Protection, Greensboro, NC). During the immersion period, the bottles were agitated briefly two times. The petioles were placed directly on filter paper without rinsing and prepared for incubation as the control treatment.

Freeze treatments were initiated by placing uncapped bottles containing five petioles each in a conventional freezer $(-15$ to $-20^{\circ} \mathrm{C}$ ) until the petioles were thoroughly frozen ( 1 to $2 \mathrm{~h}$ ). In the first of five freeze treatments, 30 petioles were thawed, washed, rinsed, dried, and prepared for incubation as described for the control treatment. To determine the effects of surface disinfestation on Colletotrichum spp. and other fungal competitors, petioles were exposed to $0.525 \%$ sodium hypochlorite $(\mathrm{NaOCl})$ for $0.5,1.0,2.0$, or $5.0 \mathrm{~min}$. Ten microliters of $25 \%$ Tween 20 (18 $\mu \mathrm{l} /$ liter) was added to each bottle prior to filling with disinfectant. The bottles were closed and agitated twice by hand during the exposure period. After treatment, the petioles were rinsed once in sterile deionized water and handled as previously described.

Petri dishes with petioles were stacked inside clear plastic crisper boxes to help retain moisture and incubated on a laboratory bench at 23 to $25^{\circ} \mathrm{C}$ under continuous fluorescent lighting. After 5 to 7 days, growth characteristic of Colletotrichum spp. easily was observed with a dissecting microscope, and appeared as pale orange to white mounds of conidia produced by acervuli. To characterize these fungi to species, one or more acervuli from each petiole was mounted in water and examined under a compound microscope. Identification was based on morphological characteristics such as spore shape and the presence or absence of setae. In doubtful cases, single-spore isolates were obtained by transferring an acervulus to $10 \mathrm{ml}$ of sterile deionized water in a $15-\mathrm{ml}$ disposable plastic test tube and shaken vigorously. One milliliter of the resulting spore suspension was spread on a petri dish containing a semiselective Colletotrichum isolation medium (37). After overnight incubation at $24^{\circ} \mathrm{C}$, newly germinated spores were transferred to potato dextrose agar (PDA; Difco Laboratories, Detroit, $\mathrm{MI})$ and incubated under constant fluorescent lighting for 5 to 7 days at $24^{\circ} \mathrm{C}$. Identifications were based on classical mycological characteristics such as colony growth rate and appearance, spore size and morphology, and the presence or absence of setae $(14,31)$. Isolates of interest were preserved at $-85^{\circ} \mathrm{C}$ in 10 to $20 \%$ glycerol (21).

The experiment was repeated six times. The number of petioles colonized by $\mathrm{Col}$ letotrichum spp. and the frequency of detection in percent was calculated for each treatment in each experiment. Frequency data $(\% / 100)$ were transformed by an arcsine square root expression prior to analysis. Data from all six experiments were combined in an analysis of variance (ANOVA) using SAS software (SAS Institute, Cary, NC). Multiple comparisons of treatment means were made using Fisher's protected least significant difference (LSD) test $(\alpha=0.05)$. Four quantitative treatments testing different times of exposure to a surface disinfectant also were examined in an analysis of covariance to determine the relationship between exposure interval and frequency of detection of Colletotrichum spp.

Treatment comparisons using inoculated strawberry petioles. In an effort to reduce variability associated with fieldgrown material, selected treatments were compared using petioles obtained from greenhouse plants inoculated with $C$. $a c u$ tatum. Strawberry runner plants (cv. Camarosa) were obtained from a California nursery, transplanted into $15-\mathrm{cm}$ round pots filled with a commercial mixture of peat moss, vermiculite, and perlite (Fafard 2 Mix, Conrad Fafard Inc., Agawam, MA), fertilized with Osmocote 14:14:14 controlled release fertilizer at $7 \mathrm{~g} /$ pot (The Scotts Co., Marysville, $\mathrm{OH}$ ), and grown at 25 to $34^{\circ} \mathrm{C}$ in the greenhouse. After 5 to 7 weeks, plants were selected at random for inoculation.

The greenhouse-grown plants were inoculated with a single-spore isolate of $C$. acutatum obtained from a diseased Camarosa fruit in 1999 (GCREC culture collection number 98-324). Cultures were grown on PDA for 6 to 8 days under continuous fluorescent lighting at $24^{\circ} \mathrm{C}$. Inoculum suspensions consisting of $5 \times 10^{4}, 5 \times 10^{3}$, and $5 \times 10^{2}$ conidia/ml were prepared in sterile deionized water with the aid of a hemacytometer. In all, 27 to 30 plants were inoculated with each suspension by spraying petioles nearly to runoff with a handheld aerosol sprayer (Chromist sprayer; Gelman Sciences, Ann Arbor, MI). A comparable group of plants was sprayed with sterile water. After treatment, the plants were incubated in closed 113-liter marine coolers (Igloo Products Corp., Houston, $\mathrm{TX})$ at 24 to $26^{\circ} \mathrm{C}$ for 2 days, and then transferred to a greenhouse.

Seven days after inoculation, apparently healthy petioles were removed from plants in each inoculation treatment and from plants treated with sterile water. Each set of petioles was divided randomly into groups of 30 to provide material for the evaluation of four petiole treatments: (i) surface disinfest in $0.525 \% \mathrm{NaOCl}$ for 1 $\mathrm{min}$, rinse once in sterile water, immerse in $0.3 \%$ paraquat for $1 \mathrm{~min}$; (ii) freeze for 1 to $2 \mathrm{~h}$ at $-15^{\circ} \mathrm{C}$, surface disinfest in $0.525 \% \mathrm{NaOCl}$ for $1 \mathrm{~min}$, rinse once in sterile water; (iii) freeze for 1 to $2 \mathrm{~h}$ at $-15^{\circ} \mathrm{C}$, surface disinfest in $0.0525 \%$ $\mathrm{NaOCl}$ for $1 \mathrm{~min}$; and (iv) rinse for $1 \mathrm{~min}$ in sterile water. All $\mathrm{NaOCl}$ solutions and the sterile water in treatment four included Tween 20 surfactant at $18 \mu \mathrm{l} /$ liter. The treatments were carried out in closed screw-cap bottles to permit periodic agitation during exposure periods. In all, 30 petioles were processed per treatment, in separate replicates of 10 petioles each. After treatment, the petioles were air dried briefly in a laminar flow hood to remove excess surface moisture, incubated for 6 to 7 days on moist filter paper in petri dishes, and observed microscopically. When sporulation characteristic of Colletotrichum spp. was observed, confirmation of $C$. acutatum was made by examining acervuli and conidia with a compound microscope.

The experiment was repeated using petioles from plants inoculated with the same isolate of C. acutatum at $5 \times 10^{3}, 5 \times 10^{2}$, and $5 \times 10^{1}$ conidia $/ \mathrm{ml}$ and plants treated with sterile water. The number of petioles colonized by $C$. acutatum in each treatment and replicate was recorded and expressed as a percentage. Frequency data 
$(\% / 100)$ were transformed by an arcsine square root expression and analyzed separately by two-way ANOVA for each inoculum level and by three-way ANOVA using the Proc Mixed procedure in SAS for each experiment. Multiple means comparisons were made by Fisher's protected LSD in the two-way analyses $(\alpha=0.05)$. Treatment, replicate, and inoculum level were included as classification variables in the three-way analyses, which included data from all inoculum levels in an experiment to increase the power of the test. The three-way analyses incorporated a Dunnett's adjustment to compare least square means from three treatments to those of the paraquat, the standard or reference treatment.

Detection of Colletotrichum spp. on planting material. Runner plants from commercial nurseries in Canada were examined during October and November 1999 and 2001 to detect latent infections of Colletotrichum spp. Plants from four nurseries in 1999 and five nurseries in 2001 were assayed using a petiole freeze protocol. One box of 500 plants was obtained from each nursery through commercial distributors in Florida. Two hundred petiole segments (each from one mature leaf/plant) were frozen for 1 to $2 \mathrm{~h}$, surface disinfested fir $1 \mathrm{~min}$ in $0.525 \% \mathrm{NaOCl}$ plus Tween 20 at $18 \mu \mathrm{l} /$ liter, rinsed in sterile water, dried, and incubated as previously described. The number of petioles colonized by Colletotrichum spp. was recorded and the species producing a large cluster of acervuli on each petiole was tentatively identified.

Pathogenicity tests. Eighteen isolates of C. gloeosporioides from petioles were tested for pathogenicity in the greenhouse. All isolates were obtained by the freeze method from healthy-appearing petioles of strawberry plants growing at GCREC. Ten were isolated in May 1999 from a small block of Camarosa plants that were not treated with fungicides active against $\mathrm{Col}$ letotrichum spp. Eight were isolated in November 1999 from various unnamed clones in a strawberry breeder's nursery sprayed regularly with captan. Although these eight isolates developed from single conidia isolated from excised acervuli, perithecia of $G$. cingulata occasionally were interspersed among acervuli on petioles colonized by $C$. gloeosporioides. Pathogenicity was assessed by injecting strawberry crowns with inoculum using a syringe (32). Commercial runner plants or rooted runner tips of $\mathrm{cv}$. Camarosa were transplanted to $15-\mathrm{cm}$ plastic pots filled with Fafard 2 potting mix, and grown on greenhouse benches for 4 to 7 weeks prior to inoculation. Inoculum was prepared from 5- to 7-day-old colonies on PDA and consisted of spore suspensions of each isolate adjusted to $1 \times 10^{6}$ conidia/ml in sterile water. Plants were inoculated by injecting a small quantity $(<0.2 \mathrm{ml})$ of spore suspension into the lower crown of each plant using a syringe fitted with a 25gauge needle. Positive controls were inoculated with a pathogenic isolate of $C$. gloeosporioides (GCREC culture collection number 98-285). Negative controls were injected with sterile water. Each isolate was used to inoculate three plants that were incubated on a greenhouse bench at 24 to $35^{\circ} \mathrm{C}$. Isolates that killed two or all three plants within 28 days were considered pathogenic. Each isolate was tested two or three times.

\section{RESULTS}

Treatment comparisons using naturally infected strawberry petioles. Naturally infected, field-grown petioles were used in six replicate experiments to compare freeze treatments to a standard paraquat treatment for the detection of Colletotrichum spp. The overall frequency of detection varied markedly from experiment to experiment, as did the distribution of species in individual experiments. Mean frequency of detection of Colletotrichum spp. ranged from $37.5 \%$ in experiment one to $4.8 \%$ in experiment six (Table 1). Not surprisingly, experiment was highly significant as a factor in the ANOVA $(P<$ $0.0001)$. Species were identified in experiments three through six. A mixture of $C$. acutatum and C. gloeosporioides was found in experiment three, with C. gloeosporioides predominating. C. acutatum was the only Colletotrichum sp. detected in experiment four. C. acutatum occurred more frequently than C. gloeosporioides in experiments five and six. A third species with falcate conidia, $C$. dermatium, also was found on one petiole in experiment six. In summary, only two species of Colletotrichum (i.e., $C$. acutatum and $C$. gloeosporioides) were identified consistently on petioles from field-grown plants in these experiments.

Both paraquat and freeze treatments significantly enhanced the detection of Colletotrichum spp. on strawberry petioles (Table 1). In contrast, a simple wash-and-rinse treatment resulted in the lowest detection levels. Colletotrichum spp. were detected on $25.6 \%$ of the paraquat-treated petioles, on average, over the six experiments. Detection levels ranged from 12.8 to $20.6 \%$ among the petiole freeze treatments. However, four freeze treatments were statistically equivalent to paraquat $(P \leq 0.05)$ and one that included a rigorous 5-min exposure to $\mathrm{NaOCl}$ resulted in significantly lower detection frequency.

There were no significant differences in mean frequency of detection of Colletotrichum spp. among the five freeze treatments. Four freeze treatments were followed by a surface disinfestation step ranging in duration from 0.5 to $5 \mathrm{~min}$. Data from these four treatments were examined in a separate analysis of covariance to determine the relationship between the time of exposure to $\mathrm{NaOCl}$ and frequency of detection of Colletotrichum spp. The model for this analysis (which included experiment as a classification variable and time as a covariate) accounted for most experimental variance $\left(R^{2}=0.8679\right)$ and was highly significant $(P<0.0001)$. In partitioning the sums of squares, the $P$ value for the covariate time was 0.0279 , indicating a significant linear relationship between time of disinfestation (min) and the transformed frequency detection of Colletotrichum spp.

Treatment comparisons using inoculated strawberry petioles. Four petiole treatments were compared for sensitivity of detection using petioles from greenhouse-grown plants inoculated with $C$. acutatum. The pathogen was detected at relatively low frequency in petioles that were washed in a solution of Tween 20 and water, but not killed, prior to incubation

Table 1. Frequency of detection of Colletotrichum spp. on naturally infected strawberry petioles

\begin{tabular}{|c|c|c|c|c|c|c|c|}
\hline \multirow[b]{2}{*}{ Treatment $^{y}$} & \multicolumn{7}{|c|}{ Petioles colonized by Colletotrichum spp. $(\%)^{\mathrm{x}}$} \\
\hline & $\operatorname{Exp} 1$ & $\operatorname{Exp} 2$ & $\operatorname{Exp} 3$ & $\operatorname{Exp} 4$ & $\operatorname{Exp} 5$ & Exp 6 & $\operatorname{Mean}^{\mathrm{z}}$ \\
\hline Paraquat & 66.7 & 30.0 & 23.3 & 23.3 & 10.0 & 0.0 & $25.6 \mathrm{a}$ \\
\hline Freeze, $\mathrm{SD}=0.5 \mathrm{~min}$ & 40.0 & 33.3 & 3.3 & 20.0 & 6.7 & 20.0 & $20.6 \mathrm{ab}$ \\
\hline Freeze, $\mathrm{SD}=1.0 \mathrm{~min}$ & 36.7 & 20.0 & 0.0 & 33.3 & 6.7 & 10.0 & $17.8 \mathrm{ab}$ \\
\hline Freeze, wash/rinse & 36.7 & 13.3 & 6.7 & 20.0 & 26.7 & 0.0 & $17.2 \mathrm{ab}$ \\
\hline Freeze, $\mathrm{SD}=2.0 \mathrm{~min}$ & 43.3 & 16.7 & 0.0 & 13.3 & 13.3 & 3.3 & $15.0 \mathrm{ab}$ \\
\hline Freeze, $\mathrm{SD}=5.0 \mathrm{~min}$ & 26.7 & 30.0 & 0.0 & 16.7 & 3.3 & 0.0 & $12.8 \mathrm{~b}$ \\
\hline Wash/rinse control & 0.0 & 0.0 & 3.3 & 0.0 & 0.0 & 0.0 & $0.6 \mathrm{c}$ \\
\hline
\end{tabular}

${ }^{\mathrm{x}}$ Thirty petioles were tested per treatment in each of six replicate experiments (exp).

${ }^{y}$ Petioles were killed by exposure to $0.3 \%$ paraquat or by freezing at $-15^{\circ} \mathrm{C}$ for 1 to $2 \mathrm{~h}$. Some freeze treatments were followed by surface disinfestation (SD) in $0.525 \% \mathrm{NaOCl}$ and rinsing.

${ }^{\mathrm{z}}$ Means followed by the same letter are not significantly different $(P \leq 0.05)$ according to a Fisher's protected least significant difference test. 
(Table 2). Detection levels were improved dramatically by freezing or paraquat treatments, which rapidly killed the host tissues. The paraquat treatment produced the highest mean detection frequency in both experiments. However, there were no significant differences between the paraquat standard and one freeze treatment in the first $(P=0.1277)$ or second $(P=$ $0.7880)$ experiment. This treatment consisted of freezing followed by surface disinfestation of the petioles in dilute $(0.0525 \%) \mathrm{NaOCl}$.

As expected, the frequency of detection was related to the concentration of conidia in the inoculum used to infect the petioles (Table 2). In the first experiment, C. acutatum was detected on all paraquat- and freeze-treated petioles previously inoculated with $5 \times 10^{4}$ conidia $/ \mathrm{ml}$. This inoculum level was not repeated in the second experiment. With one exception, detection frequencies were consistently higher in petioles inoculated with $5 \times 10^{3}$ conidia $/ \mathrm{ml}$ than in those inoculated with $5 \times 10^{2}$. Even at the lower inoculum level, $C$. acutatum was found on more than $66 \%$ of the freezetreated petioles. This high level of detection was comparable to petioles treated with paraquat. In addition, both methods detected background levels of $C$. acutatum in petioles from noninoculated plants.

Detection of Colletotrichum spp. on planting material. Shipments of runner plants from four Canadian nurseries were tested for latent petiole infections in 1999 and 2001 using a petiole-freeze method. Three of the nurseries sampled in 1999 were sampled again in 2001. Colletotrichum spp. were not detected on petioles obtained from any nursery in 1999. In 2001, C. acutatum was found on 0.5, 2.0, and $36.5 \%$ of the petioles from three nurseries, but no Colletotrichum spp. were detected on petioles from the fourth nursery. In addition, $C$. dermatium was found on $10.5 \%$ of the petioles from the nursery with $2.0 \%$ incidence of $C$. acutatum. Among the 200 plants sampled from the nursery with the highest colonization rate (i.e., with C. acutatum detected on $36.5 \%$ of the petioles) four petioles with conspicuous anthracnose-like lesions were found. These diseased petioles were frozen, thawed, and surface disinfested for 2 $\min$ in $0.0525 \% \mathrm{NaOCl}$ without subsequent rinsing. After 4 to 5 days of incubation, C. acutatum sporulated profusely in the lesions of two of these petioles.

Pathogenicity tests. Petiole isolates of C. gloeosporioides were screened for pathogenicity by inoculating the crowns of strawberry plants in replicated greenhouse tests. Eight of nine isolates from an untreated block of Camarosa plants were nonpathogenic in these tests (Table 3). One isolate gave inconsistent results in two tests, but was pathogenic in a third test. In contrast, seven of eight isolates from strawberry cultivars and crosses in a plant breeder's nursery were consistently pathogenic in both tests. In each test, plants injected with sterile water remained healthy, whereas those injected with a pathogenic isolate of $C$. gloeosporioides usually were killed within 4 weeks of inoculation.

\section{DISCUSSION}

Colletotrichum spp. can be detected and tentatively identified on latently infected strawberry plants in 5 to 7 days using a petiole-freeze method. The sensitivity of this method was statistically equivalent to the paraquat standard in all of our experiments. Using the petiole-freeze method, $C$. acutatum and $C$. gloeosporioides were detected on healthy petioles taken from strawberry plants grown under commercial conditions in Florida. However, C. acutatum and C. dermatium, but not C. gloeo-

Table 3. Pathogenicity of Colletotrichum gloeosporioides isolates from strawberry petioles in greenhouse inoculation tests

\begin{tabular}{lcccc}
\hline & \multicolumn{3}{c}{ Number of dead plants $^{\mathbf{x}}$} & \\
\cline { 2 - 4 } Source, isolate $^{\mathbf{y}}$ & Test 1 & Test 2 & Test 3 & Pathogenicity $^{\mathbf{z}}$ \\
\hline Camarosa block & 0 & 0 & $\ldots$ & - \\
$98-16$ & 0 & 0 & $\ldots$ & - \\
$98-17$ & 0 & 0 & $\ldots$ & - \\
$98-18$ & 0 & 0 & $\ldots$ & - \\
$98-19$ & 0 & 0 & $\ldots$ & - \\
$98-20$ & 0 & 0 & $\ldots$ & - \\
$98-22$ & 2 & 0 & 0 & - \\
$98-23$ & 0 & 0 & $\ldots$ & + \\
$98-24$ & 3 & 0 & 2 & - \\
$98-25$ & 0 & 0 & $\ldots$ & + \\
Breeder nursery & & & & + \\
$99-8$ & 3 & 3 & $\ldots$ & + \\
$99-9$ & 0 & 0 & $\ldots$ & + \\
$99-10$ & 3 & 3 & $\ldots$ & + \\
$99-11$ & 3 & 3 & $\ldots$ & + \\
$99-12$ & 3 & 3 & $\ldots$ & + \\
$99-13$ & 3 & 3 & $\ldots$ & \\
$99-14$ & 3 & 3 & $\ldots$ & + \\
$99-15$ & 3 & 2 & & + \\
\hline
\end{tabular}

${ }^{\mathrm{x}}$ Number of plants (out of three/test) that died within 28 days of inoculation.

y Isolates 98-16 through 98-25 were isolated from strawberry petioles in an unsprayed block of cultivar Camarosa; isolates 99-8 through 99-15 from unnamed clones in a breeder's nursery.

${ }^{\mathrm{z}}$ Isolates that killed two or more plants in two tests were considered pathogenic.

Table 2. Frequency of detection of Colletotrichum acutatum on strawberry petioles 7 days after inoculation

\begin{tabular}{|c|c|c|c|c|c|c|c|}
\hline \multirow[b]{2}{*}{ Petiole treatment ${ }^{\mathrm{x}}$} & \multicolumn{7}{|c|}{ Petioles infected with $C$. acutatum at specified inoculum level $(\%)^{\mathrm{w}}$} \\
\hline & $5 \times 10^{4}$ & $5 \times 10^{3}$ & $5 \times 10^{2}$ & $5 \times 10^{1}$ & Control & Mean & Proby $^{y}$ \\
\hline \multicolumn{8}{|l|}{ Experiment 1} \\
\hline $\mathrm{NaOCl}(0.525 \%)$, rinse, paraquat & $100.0 \mathrm{a}$ & $100.0 \mathrm{a}$ & $80.0 \mathrm{a}$ & $\ldots$ & $26.7 \mathrm{a}$ & 76.7 & Ref \\
\hline Freeze, $\mathrm{NaOCl}(0.525 \%)$, rinse & $100.0 \mathrm{a}$ & $90.0 \mathrm{a}$ & $66.7 \mathrm{a}$ & $\ldots$ & $3.3 \mathrm{~b}$ & 65.0 & 0.0048 \\
\hline Freeze, $\mathrm{NaOCl}(0.0525 \%)$ & $100.0 \mathrm{a}$ & $90.0 \mathrm{a}$ & $73.3 \mathrm{a}$ & $\ldots$ & $16.7 \mathrm{a}$ & 70.0 & 0.1277 \\
\hline Water wash & $56.7 \mathrm{~b}$ & $10.0 \mathrm{~b}$ & $13.3 \mathrm{~b}$ & $\ldots$ & $0.0 \mathrm{~b}$ & 20.0 & 0.0001 \\
\hline \multicolumn{8}{|l|}{ Experiment 2} \\
\hline $\mathrm{NaOCl}(0.525 \%)$, rinse, paraquat & $\ldots$ & $100.0 \mathrm{a}$ & $90.0 \mathrm{a}$ & $10.0 \mathrm{~b}$ & $23.3^{z}$ & 55.8 & Ref \\
\hline Freeze, $\mathrm{NaOCl}(0.525 \%)$, rinse & $\ldots$ & $100.0 \mathrm{a}$ & $76.7 \mathrm{a}$ & $3.3 \mathrm{bc}$ & 10.0 & 47.5 & 0.0406 \\
\hline Freeze, $\mathrm{NaOCl}(0.0525 \%)$ & $\ldots$ & $100.0 \mathrm{a}$ & $73.3 \mathrm{a}$ & $36.7 \mathrm{a}$ & 6.7 & 54.2 & 0.7880 \\
\hline Water wash & $\ldots$ & $23.3 \mathrm{~b}$ & $0.0 \mathrm{~b}$ & $0.0 \mathrm{c}$ & 0.0 & 5.8 & 0.0001 \\
\hline
\end{tabular}

${ }^{w}$ In each experiment, 30 petioles were tested per treatment and inoculum level in groups of 10 petioles each. Inoculum level in conidia/ml. Control plants were treated with sterile water. Separate analyses of variance were performed for each inoculum level in each experiment. Within an experiment, means in a column followed by the same letter are not significantly different according to a Fisher's protected least significant difference test $(P \leq 0.05)$.

x Petioles were killed by exposure to $0.3 \%$ paraquat or by freezing for 1 to $2 \mathrm{~h}$ at $-15^{\circ} \mathrm{C}$, but were not killed in the water wash treatment. Sodium hypochlorite $(\mathrm{NaOCl}$ at 0.525 or $0.0525 \%$ concentration) was used for surface disinfestation.

y Dunnett's test probabilities that the least square treatment means are the same as the (reference) paraquat treatment mean.

z The analysis of variance $F$ test was not significant; multiple means comparisons are not presented. 
sporioides, were detected on strawberry transplants produced in Canadian nurseries and shipped to Florida strawberry growers in 2001. Both C. acutatum and C. gloeosporioides are major pathogens of strawberry and numerous other crops, but not all isolates of C. gloeosporioides recovered from strawberry petioles were pathogenic to strawberry in greenhouse tests.

In the first series of experiments, petiole-freeze treatments were followed by a conventional surface disinfestation in $0.525 \% \mathrm{NaOCl}$ and a sterile water rinse. Surface disinfestation was carried out to eliminate possible cross-contamination between petioles during processing, and to destroy common saprophytes on the petiole surface that could inhibit or obscure Colletotrichum spp. For these same reasons, a surface disinfestation step often is performed before treating plant material with paraquat $(2,6,12)$. In this study, no significant differences were detected between freeze treatments involving different intervals of surface disinfestation (Table 1). However, the length of exposure to $0.525 \% \mathrm{NaOCl}$ was negatively correlated with the frequency of detection. Therefore, if surface disinfestation is carried out, relatively short exposure intervals (e.g., 0.5 to $1 \mathrm{~min}$ ) are preferable to longer intervals for the assay of strawberry petioles. Longer exposure periods frequently are reported in conjunction with the paraquat method $(2,6)$ and should be examined for their effects on assay sensitivity.

In the second set of experiments, the concentration of $\mathrm{NaOCl}$ was reduced 10fold to $0.0525 \%$ in one treatment and the water rinse step was eliminated. Gindrat et al. (12) used the same concentration of $\mathrm{NaOCl}$ in conjunction with paraquat to identify yeasts and filamentous fungi associated with healthy wheat leaves. In our study, C. acutatum was detected on freezetreated petioles surface disinfested in $0.0525 \% \mathrm{NaOCl}$ as frequently as on paraquat-treated petioles. However, when thawed petioles were surface disinfested in $0.525 \% \mathrm{NaOCl}$ and rinsed in sterile water, C. acutatum was detected at lower frequencies than the paraquat standard. The petioles used in these experiments were inoculated 7 days before the assay, and may have been only superficially colonized by $C$. acutatum. Presumably, this growth would be more susceptible to eradication by $0.525 \%$ than $0.0525 \%$ $\mathrm{NaOCl}$. In a related experiment, conidia of C. acutatum suspended in $0.0525 \% \mathrm{NaOCl}$ were killed completely within $1 \mathrm{~min}$ (data not shown). In addition to increasing assay sensitivity, the milder surface disinfestation procedure also should prevent crosscontamination when multiple petioles are processed together.

Both C. acutatum and C. gloeosporioides were detected on petioles taken from established strawberry plants growing under field conditions in Florida. In contrast, C. acutatum, but not $C$. gloeosporioides, was detected on petioles of transplants from Canadian nurseries. These findings are in agreement with the ecological characteristics of the two species. $C$. acutatum produces more conidia and has a shorter latent period at lower temperatures than C. gloeosporioides (18) and may be better adapted to mild summer conditions in Canadian nursery areas. Members of the C. gloeosporioides species aggregate infect an extremely wide range of hosts (9), many of which are restricted to tropical and subtropical habitats. This study supports the argument that anthracnose fruit rot epidemics commonly develop from planting material infected by $C$. acutatum in the nursery. Outbreaks of anthracnose crown rot caused by $C$. gloeosporioides or $C$. fragariae also may develop from infected planting materials $(17,25)$. Our failure to detect these fungi on northern nursery plants may be related to sample size (i.e., only four nurseries were sampled over two seasons) or tissue specificity (e.g., a tendency for infections to develop more frequently in crowns than on petioles). However, C. gloeosporioides was detected readily on petioles of Floridagrown strawberry plants, and both species reportedly produce anthracnose lesions on strawberry petioles $(4,31)$. Native populations of C. gloeosporioides on non-strawberry hosts should not be overlooked as possible sources of inoculum for anthracnose crown rot of strawberry (24).

Treated petioles typically were observed after 5 to 7 days of incubation. This interval permitted Colletotrichum spp. to grow without being obscured by mycelium of saprophytic fungi. In experiments utilizing petioles from field-grown strawberry plants, spherical pubescent structures occasionally were found interspersed among acervuli of $C$. gloeosporioides (34). When incubated for an additional 5 to 7 days, these structures produced ascospores and were identified as perithecia of $G$. cingulata $(15,40)$. Single ascospores isolated from these perithecia produced typical colonies of $C$. gloeosporioides on PDA. This is the first report of G. cingulata occurring naturally on strawberry plant material, and suggests that sexual recombination of $C$. gloeosporioides populations may occur in Florida strawberry fields.

The freeze method eliminates the need for handling paraquat in the laboratory and provides an alternative for detecting latent infections of Colletotrichum spp. on strawberry plants. Freezing has been used to monitor survival of $C$. acutatum on inoculated strawberry leaves (19) and to detect latent infections of Monilinia fructicola on immature stone fruit (27). Additional studies are needed to determine if other species of Colletotrichum and other genera of plant-pathogenic fungi can be detected by this method. Alternaria spp., Fusarium spp., and Phomopsis obscurans grew out of freeze-treated strawberry petioles during our study, suggesting that these genera could be detected by freezing. However, Botrytis cinerea seldom was found, even though this pathogen is readily detected on paraquat-treated strawberry leaves (35) and grape berries (12). Freezing should be compared with paraquat for each hostpathogen combination of interest to determine which provides the best assay.

\section{ACKNOWLEDGMENTS}

We thank S. Staton, J. Souder, H. Darhower, T. Seijo, and A. Whidden for their assistance with and contributions to the petiole assay method.

\section{LITERATURE CITED}

1. Anonymous. 1998. Strawberry black spot Central Science Laboratory. Department for Environment, Food, and Rural Affairs publication PB 3595 (b). Ministry of Agriculture, Fisheries, and Food, York, UK.

2. Biggs, A. R. 1995. Detection of latent infections in apple fruit with paraquat. Plant Dis. 79:1062-1067.

3. Bosshard, E. 1997. Why is Colletotrichum acutatum a quarantine organism and C. gloeosporioides and $C$. fragariae are not? Proc. Third Int. Strawberry Symp. Acta Hortic. 439:799-802.

4. Brooks, A. N. 1931. Anthracnose of strawberry caused by Colletotrichum fragariae, n. sp. Phytopathology 21:739-744.

5. Brooks, A. N. 1935. Anthracnose and wilt of strawberry caused by Colletotrichum fragariae. (Abstr.) Phytopathology 25:973.

6. Cerkauskas, R. F. 1988. Latent colonization by Colletotrichum spp: Epidemiological considerations and implications for mycoherbicides. Can. J. Plant Pathol. 10:297-310.

7. Cook, R. T. 1993. Strawberry black spot caused by Colletotrichum acutatum. Pages 301-304 in: British Crop Protection Council Monograph No. 54: Plant Health and the European Single Market. D. Ebbels, ed. Hampshire UK.

8. Cook, R. T. A., and Popple, S. C. 1984. Strawberry black spot caused by Colletotrichum spp. (Abstr.). Agric. Dev. Advis. Serv. Plant Pathol. Tech. Conf., Harrogated, UK.

9. Farr, D. F., Bills, G. F., Chamuris, G. P., and Rossman, A. Y. 1989. Fungi on Plants and Plant Products in the United States. American Phytopathological Society Press. St. Paul, MN.

10. Freeman, S. 1996. Occurrence and identification of Colletotrichum acutatum responsible for strawberry anthracnose in Israel. (Abstr.) Phytoparasitica 24:137.

11. Freeman, S., and Katan T. 1997. Identification of Colletotrichum species responsible for anthracnose and root necrosis of strawberry in Israel. Phytopathology 87:516-521.

12. Gindrat, D., and Pezet, R. 1994. Paraquat: a tool for the quick development of latent fungal infection and endophytic fungi (In French with English abstract). J. Phytopathol. 141:86-98.

13. Gubler, W. D., and Eastburn, D. M. 1988. Research progress report: Anthracnose in California. Adv. Strawberry Prod. 7:47-50.

14. Gunnell, P. S., and Gubler, W. D. 1992. Taxonomy and morphology of Colletotrichum species pathogenic to strawberry. Mycologia 84:157-165.

15. Hanlin, R. T. 1990. Illustrated Genera of Ascomycetes: Volume I. American Phytopathological Society Press, St. Paul, MN.

16. Howard, C. M. 1983. Black leaf spot phase of strawberry anthracnose caused by Colletotrichum gloeosporioides $(=C$. fragariae $)$. Plant Dis. 67:1144-1146.

17. Howard, C. M., Mass, J. L., Chandler, C. K., 
and Albregts, E. E. 1992. Anthracnose of strawberry caused by the Colletotrichum complex in Florida. Plant Dis. 76:976-981.

18. King, W. T., Madden, L. V., Ellis, M. A., and Wilson, L. L. 1997. Effects of temperature on sporulation and latent period of Colletotrichum spp. infecting strawberry fruit. Plant Dis. 81:77-84.

19. Leandro, L. F. S., Gleason, M. L., Nutter, F. W., Jr., Wegulo, S. N., and Dixon, P. M. 2002. Influence of temperature and wetness duration on conidia and appressoria of Colletotrichum acutatum on symptomless strawberry leaves. Phytopathology 93:513-520.

20. Legard, D. E. 2000. Colletotrichum diseases of strawberry in Florida. Pages 290-299 in: Colletotrichum: Host Specificity, Pathology, and Host-Pathogen Interaction. D. Prusky, S. Freeman, and M. B. Dickman, eds. American Phytopathological Society Press, St. Paul, MN.

21. Legard, D. E., and Chandler, C. K. 2000. Cryopreservation of strawberry pathogens in a $-95^{\circ} \mathrm{C}$ mechanical ultra-low temperature freezer. HortScience 35:1357.

22. Mass, J. L. 1998. Compendium of Strawberry Diseases, 2nd ed. American Phytopathological Society Press, St. Paul, MN.

23. Maas, J. L., and Palm, M. E. 1997. Occurrence of anthracnose irregular leaf spot, caused by Colletotrichum acutatum, on strawberry in Maryland. Adv. Strawberry Res. 16:68-70

24. MacKenzie, S. J., Xiao, C. L., and Legard, D. E. 2001. Genetic analysis suggests that non- strawberry hosts are a source of inoculum for Colletotrichum crown rot of strawberry. (Abstr.) Phytopathology 91:S57

25. McInnes, T. B., and Black, L. B. 1992. Disease-free plants for management of strawberry anthracnose crown rot. Plant Dis. 76:260-264.

26. Mertely, J. C., and Legard, D. E. 2000. A freezing technique to detect latent infections of Colletotrichum spp. on strawberry. (Abstr.) Phytopathology 90:S53

27. Michailides, T. J., Morgan, D. P., and Felts, D. 2000. Detection and significance of symptomless latent infection of Monilinia fructicola in California stone fruits. (Abstr.) Phytopathology 90:S53.

28. Parikka, P. 2001. First report of Colletotrichum acutatum on strawberry in Finland. Plant Dis. 85:923.

29. Sinclair, J. B. 1991. Latent infection of soybean plants and seeds by fungi. Plant Dis. 75:220-224.

30. Smith, B. J. 1998. Anthracnose leaf spot and irregular leaf spot, Anthracnose fruit rot (black spot), and Anthracnose crown rot. Pages 2425, 31-33, and 46-48 in: Compendium of Strawberry Diseases, 2nd ed. J. L. Maas, ed. American Phytopathological Society Press, St. Paul, MN.

31. Smith, B. J., and Black, L. L. 1990. Morphological, cultural, and pathogenic variation among Colletotrichum species isolated from strawberry. Plant Dis. 74:69-76.

32. Smith, B. J., Black, L. L., and Galletta, G. J.
1990. Resistance of Colletotrichum fragariae in strawberry affected by seedling age and inoculation method. Plant Dis. 74:1016-1021.

33. Sreenivasaprasad, S., Brown, A. E., and Mills, P. R. 1992. DNA sequence variation and interrelationships among Colletotrichum species causing strawberry anthracnose. Physiol. Mol. Plant Pathol. 41:265-281.

34. Sutton, B. C. 1992. The genus Glomerella and its anamorph Colletotrichum. Pages 1-26 in: Colletotrichum: Biology, Pathology, and Control. J. A. Bailey and M. J. Jeger, eds. CAB International, Wallingford, UK.

35. Sutton, J. C., and Peng, C. 1993. Biocontrol of Botrytis cinerea in strawberry leaves. Phytopathology 83:615-621.

36. Ureña-Padilla, A. R., MacKenzie, S. J., Bowen, B. W., and Legard, D. E. 2002. Etiology and population genetics of Colletotrichum spp. that cause crown and fruit rot of strawberry. Phytopathology 92:1245-1252.

37. Ureña-Padilla, A. R., Mitchell, D. J., and Legard, D. E. 2001. Oversummer survival of inoculum for Colletotrichum crown rot in buried strawberry crown tissue. Plant Dis. 85:750754.

38. Verhoeff, K. 1974. Latent infections by fungi. Annu. Rev. Phytopathol. 12:99-110.

39. von Arx, J. A. 1957. Die Arten de Gattung Colletotrichum Cda. Phytopathol. Z. 29:413468.

40. von Arx, J. A. 1987. Plant Pathogenic Fungi. J. Cramer, Berlin. 